\title{
Temporal Response of Immunoreactive Erythropoietin to Acute Hypoxemia in Fetal Sheep
}

\author{
JOHN A. WIDNESS, KARI A. TERAMO, GISELA K. CLEMONS, JOSEPH F. GARCIA,' \\ RALPH L. CAVALIERI, GEORGE J. PIASECKI, BENJAMIN $\Upsilon$. JACKSON, JOHN B. SUSA, AND \\ ROBERT SCHWARTZ \\ Department of Pediatrics, Rhode Island Hospital; Department of Obstetrics/Gynecology, Women and Infants \\ Hospital of Rhode Island; Department of Surgery and the Surgical Service, Providence VA Hospital; Brown \\ University Program in Medicine, Providence, Rhode Island 02902; and Lawrence Berkeley Laboratory, \\ University of California, Berkeley, California 94720
}

\begin{abstract}
Acute hypoxemia was produced in chronically catheterized sheep fetuses to determine the response time necessary to increase plasma immunoreactive erythropoietin $(E p)$ concentration. Sodium nitrite $(0.2 \mathrm{mM})$ was infused via a fetal vein to induce fetal hypoxemia. The resultant fetal methemoglobinemia was associated with a predictable, incremental decrease in arterial oxygen content. Twelve nitrite infusions were performed in eight fetal sheep preparations (gestational ages 115-146 days). Mean methemoglobin level increased to $33 \%$ of total $\mathrm{Hb}$ after 1 $2 \mathrm{~h}$ of $\mathrm{NaNO}_{2}$ infusion. These results were compared to those obtained in nine control studies in eight fetuses in which no change was observed for plasma $\mathrm{Ep}$, arterial oxygen content, $\mathrm{PaO}_{2}, \mathrm{pH}_{\mathrm{a}}$, or whole blood lactate. In the nitrite infused group, however, a significant and progressive increase in mean plasma $\mathrm{Ep}$ level over baseline levels was observed during the 4th and 5th $h$ of hypoxemia $(p<$ 0.01 ). This change in Ep was significantly greater compared to the control group. These results, however, were confounded by the concomitant development of a lactic acidemia secondary to the fetal hypoxemia. To examine the theoretic possibility that lactic acidemia may primarily affect fetal Ep levels, an additional group of five fetuses was infused with L-lactic acid for the same time period. Although the decrements in $\mathrm{pH}_{\mathrm{a}}$ and whole blood lactate levels achieved in these fetuses were in excess of those observed during the nitrite infusions, this possibility was ruled out since no change in fetal plasma Ep levels occurred. We conclude that during the 4 th $h$ of acute fetal hypoxemia a predictable, progressive increase in plasma Ep level is observed. This response of plasma Ep to hypoxemia in late gestation fetal sheep is qualitatively similar to that observed in adult animals, thus demonstrating developmental maturity of the fetus. (Pediatr Res 20: 1519, 1986)
\end{abstract}

\section{Abbreviations}

Ep, erythropoietin

Met $\mathrm{Hb}$, methemoglobin

$\mathrm{CaO}_{2}$, arterial oxygen content

PCV, packed cell volume

ANOVA, analysis of variance

Received April 9, 1985; accepted August 14, 1985

Address correspondence and reprints, John A. Widness, M.D., Department of Pedatrics, Rhode Island Hospital, Providence, RI 02902.

Supported in part by Grants from the NIH (NICHHD-11343, NHLBI-22469),

The Hood Foundation, and the Rhode Island Hospital Research Fund.

${ }^{1}$ Deceased.
Ep is considered to be the primary hormone controlling erythropoiesis in both the adult and fetus (1-3). Tissue hypoxemia results in increased Ep production which is reflected by an increase in plasma Ep levels. Since Ep does not cross the placenta $(4,5)$, increased fetal plasma levels of Ep are indicative of fetal hypoxemia. Previous studies in fetal animals have been done using bioassay techniques which require large blood samples and which lack specificity and sensitivity (6). As such, these methods have been unsuitable for sequential fetal studies in which more precise timing of plasma Ep changes can be documented.

The recent development of a highly sensitive, specific and reproducible radioimmunoassay technique to measure Ep (7) has permitted sequential studies using $100-\mu 1$ samples of plasma. The purpose of the present study was to establish the temporal response of immunoreactive $\mathrm{Ep}$ in the fetal sheep. Data from such studies have implications for the interpretation of plasma Ep levels measured in the human fetus during the peripartum period, a critical time period during which the fetus is at risk for becoming hypoxemic.

\section{MATERIALS AND METHODS}

Fetal sheep preparations. Time dated, mixed breed pregnant sheep were studied between 115 and 146 days of gestation (term gestation 145-150 days). Fifteen pregnant ewes underwent operation, including nine with twin pregnancies. Eighteen of the 24 fetuses had catheters implanted. Six of the twin pregnancies had only one twin catheterized. Depending on the orientation of the fetus at surgery, arterial and venous catheters were secured in either the femoral or cervical vessels. Catheters were brought out through a maternal flank incision and coiled in a protective pouch. Antibiotics (ampicillin and chloramphenicol) were administered at surgery and thereafter on sampling days. Catheter patency was maintained using heparanized normal saline (1000 $\mathrm{U} / \mathrm{ml}$ ) at the conclusion of each day's sampling. Postoperatively animals were allowed a minimum of 3 days recovery before being studied. Some fetuses were studied more than once. In these individuals there was an interval of 2 or more days before being restudied.

Nitrite infusions. A total of eight fetuses was subjected to 12 nitrite infusions, all lasting 5 hours. All fetuses had preinfusion $\mathrm{PaO}_{2}$ values $\geq 15.0 \mathrm{~mm} \mathrm{Hg}$ and $\mathrm{pH}$ values $\geq 7.30$ on the day of the study and all were observed for a $60-$ to $90-$ min period prior to nitrite infusion. During this baseline period, the following laboratory determinations were made at least twice on fetal arterial whole blood: $\mathrm{pH}_{\mathrm{a}}, \mathrm{PaO}_{2}, \mathrm{PaCO}_{2}$, lactate, $\mathrm{CaO}_{2}$, Met $\mathrm{Hb}$, and PCV. Arterial plasma was frozen for subsequent Ep analyses. An intravenous infusion of $0.2 \mathrm{mM}$ sodium nitrite was then 
begun with a mean priming infusion dose of $1.15 \mathrm{mM}$ (range $0.6-1.9 \mathrm{mM}$ ) given over 20 to $90 \mathrm{~min}$ to rapidly increase Met $\mathrm{Hb}$ level. This was followed by a slower maintenance infusion of $0.2-0.4 \mathrm{mM} / \mathrm{h}$. The total nitrite dose was variable (mean and range $2.10 \mathrm{mM}, 0.74-3.50)$ as was the duration of its administration $(3.62 \mathrm{~h}, 1.0-5.0)$. To avoid fetal demise due to progressive lactic acidemia, adjustments of the nitrite infusion rate were sometimes made. These were based on the immediately available measurements of Met $\mathrm{Hb}, \mathrm{pH}_{\mathrm{a}}$, and $\mathrm{CaO}_{2}$.

$L$-Lactic acid infusions. In five of the 10 nitrite infusions, a significant fetal lactic acidemia developed. To exclude this as a primary causal factor for the changes observed in plasma Ep levels, five additional fetuses were infused with $2 \mathrm{M} \mathrm{L}$-lactic acid. This was done over $5 \mathrm{~h}$ at infusion rates of $3.5-4.5 \times 10^{-2} \mathrm{M} / \mathrm{h}$ in order to achieve comparable levels of lactic acidemia to those observed during nitrite infusion. On a previous day, two of these had been infused with normal saline at identical fluid rates while the remaining three were infused with saline 2-3 days later. The same laboratory measurements were made as in the nitrite infused group.

Control studies. Eight control fetuses were studied nine times for 6- to 7-h periods identical to the nitrite and L-lactic acid infused animals. Five of the nine studies included the five saline infused fetuses from the lactate infusion group. This was done since there was no demonstrable difference in any of the measured parameters for this group when compared to four other control fetuses studied without saline infusion.

Assays. Met $\mathrm{Hb}$ was determined on whole blood within 15 min of sampling using a modified microspectrophotometric method (8). Arterial $\mathrm{Po}_{2}, \mathrm{PCO}_{2}$, and pH were measured at $37^{\circ} \mathrm{C}$ using a Corning 165 Blood Gas Analyzer. $\mathrm{CaO}_{2}$ was determined in duplicate with a Lex- $\mathrm{O}_{2}$-Con-TL Analyzer. Lactate was measured using a spectrophotometric assay from perchloric acid treated whole blood using Sigma reagents (Sigma Chemical Co., St. Louis, MO). PCV was measured on whole blood samples centrifuged for $5 \mathrm{~min}$ at $10,000 \times g$ in microcapillary tubes.

Ep levels were determined using a double antibody radioimmunoassay technique (7). Serial dilutions of sheep plasma samples paralleled sheep Ep reference standards (Connaught Step III). Linear values for sheep Ep concentrations were obtained between 10 and $400 \mathrm{mU} / \mathrm{ml}$. Intra- and interassay coefficients of variation for the pools of sheep plasma with low Ep titers were 12.5 and $8.0 \%$, while those for high titers were 10.6 and $13.3 \%$.

Fetal heart rate and mean arterial blood pressure were measured continuously using Statham p $23 \mathrm{Db}$ transducers attached to a Hewlett-Packard 7700 Polygraph Recorder. Calibration of the blood pressure transducer was performed at the estimated mid-fetal level and readings were taken with the ewe standing quietly without correction for amniotic fluid pressure.

Data analyses. The time interval used in the analyses of the study parameters was $1 \mathrm{~h}$. If a study parameter was determined more than once in a given hour, the mean value was used.

For comparisons between and within study groupings, the statistical analyses used included paired and unpaired $t$ test, and one- and two-way ANOVA for multiple comparisons. When significant differences were detected using ANOVA, within group comparisons of different intervals were tested using Dunnett's or Newman-Keuls' Comparison Test as indicated. Linear regression analysis was also utilized.

\section{RESULTS}

Preinfusion laboratory data. Plasma Ep levels determined during the preinfusion period (h 0 ) varied greatly (mean \pm SD $31 \pm$ $34 \mathrm{mU} / \mathrm{ml}$; range $3-249 \mathrm{mU} / \mathrm{ml}$; Table 1). Thus, to reduce skewness, Ep values were converted to their logarithmic equivalents for purposes of analyses. The variability in the preinfusion plasma Ep values was most evident in the nitrite infusion group. Furthermore, when the preinfusion $\log \mathrm{Ep}$ values of the nitrite group were compared to the contr 1 group, significantly higher values were observed $\left(\mathrm{F}_{2,23}=7.56 ; p<0.05\right.$ using Newman Keuls' Comparison Test) (Table 1).

Although the preinfusion $\mathrm{CaO}_{2}$ values were not measurably different $\left(5.68 \pm 1.18\right.$ versus $6.40 \pm 0.91$ vol $\left.\% ; F_{2,23}=1.29\right)$, the preinfusion $\mathrm{PaO}_{2}$ values tended to be higher in the nitrite group $\left(19.3 \pm 2.5\right.$ versus $16.4 \pm 3.3 \mathrm{~mm} \mathrm{Hg} ; \mathrm{F}_{2.23}=4.21 ; p<$ $0.06)$. These findings might be explained in part by the disproportionate number of nitrite infusion studies in which blood sampling was done using the carotid instead of the femoral artery (7/12 nitrite infused versus $0 / 9$ control) since the $\mathrm{CaO}_{2}$ and $\mathrm{PaO}_{2}$ in the ascending aorta have been shown to average $1.0 \mathrm{vol} \%$ and $1-2 \mathrm{~mm} \mathrm{Hg}$ higher, respectively, than in the simultaneously sampled descending aorta (9).

The control group tended to have a higher PCV $(35.5 \pm 6.3$ versus $\left.29.7 \pm 2.8 \% ; \mathrm{F}_{2,23}=4.26 ; p<0.06\right)$ and was studied at a

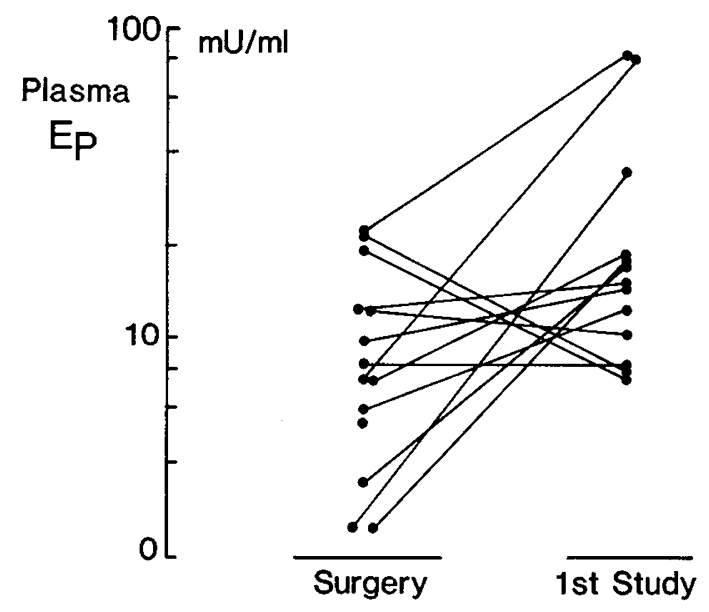

Fig. 1. Paired plasma Ep levels in 13 fetuses studied at surgical catheter implantation and during the baseline period of the first study.

Table 1. Summary of plasma Ep values by group (mean $\pm S D$ )

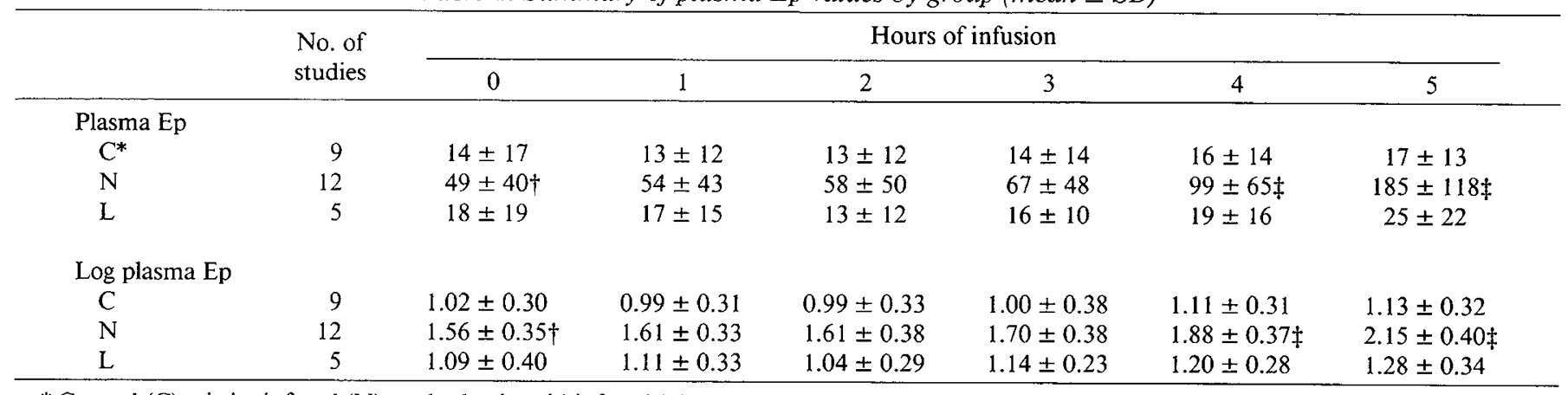

* Control (C), nitrite infused $(\mathrm{N})$, and L-lactic acid infused (L).

$\dagger p<0.05$ compared to the control group (one-way ANOVA using Newman-Keuls' comparison test).

$\ddagger p<0.01$ compared to $0 \mathrm{~h}$ (repeated measures ANOVA using Dunnett's comparison test). 

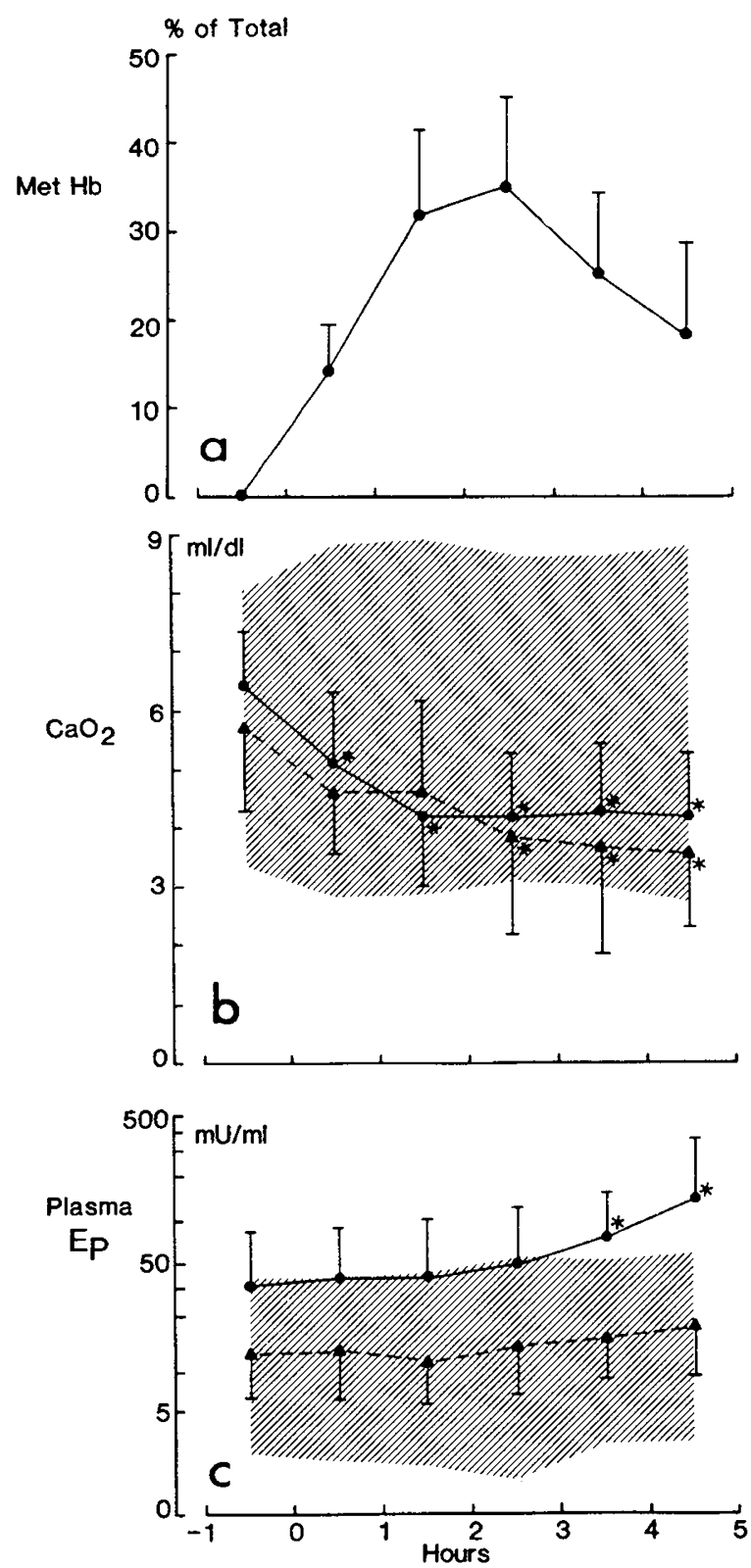

Fig. 2. Mean changes over time in $\mathrm{Met} \mathrm{Hb}(a), \mathrm{CaO}_{2}(b)$, and plasma Ep $(c)$ in control $(n=9$, cross-hatched areas $\pm 2 \mathrm{SD})$, nitrite infused ( $n$ $=12, \bullet \cdots \bullet)$, and L-lactic acid infused $(n=5, \mathbf{\Delta} \cdot \cdots \mathbf{\Delta})$ groups of fetuses. The bar shown for the nitrite and L-lactic acid groups represents $1 \mathrm{SD}$. Significant change from preinfusion baseline values using Dunnett's procedure $(p<0.01)$ is indicated by an asterisk.

greater time interval after the initiation of surgery $(14 \pm 7.8$ versus $7 \pm 2.7$ days; $\mathrm{F}_{2.23}=4.79 ; p<0.05$ ). Hence, the control fetuses may have recovered more completely from the stress of surgery. As further evidence that postoperative recovery time may influence preinfusion Ep levels, fetuses which had plasma sampled for Ep determinations at the time of initial surgery were retrospectively analyzed. These included 13 of the 18 study fetuses. All had plasma drawn between 1.5 and $2.5 \mathrm{~h}$ of the initiation of the anesthesia. There was no difference in the intraoperative Ep levels for those fetuses subsequently studied first with nitrite or saline ( $11 \pm 8$ versus $9 \pm 6 \mathrm{mU} / \mathrm{ml}$, unpaired $t$ test). However, when the intraoperative $\log$ Ep levels were compared to preinfusion levels measured 3-7 days later, the intraoperative $\mathrm{Ep}$ values were significantly lower $(p<0.01$, paired $t$ test; Fig. 1).

Preinfusion baseline $\log$ Ep values of all three study groups were combined and correlated with the other measured variables:
$\mathrm{PCV}, \mathrm{CaO}_{2}, \mathrm{PaO}_{2}, \mathrm{PaCO}_{2}, \mathrm{pH}_{2}$, and heart rate. No significant associations were found.

Control studies. During the 6- to 7-h study period, the control group of fetuses manifested no change in plasma Ep, $\mathrm{PaO}_{2}, \mathrm{CaO}_{2}$, $\mathrm{pH}_{\mathrm{a}}$, arterial whole blood lactate, heart rate, or mean arterial blood pressure (Figs. 2 and 3).

Experimental studies. In the nitrite infusion group, Met $\mathrm{Hb}$ levels increased incrementally during the first $2 \mathrm{~h}$ of the sodium nitrite infusion to levels which were above $30 \%$ of total $\mathrm{Hb}$ (Fig. $2 a$ ). These levels were maintained during the $3 \mathrm{rd} \mathrm{h}$ but subsequently decreased during the final $2 \mathrm{~h}$ of study. $\mathrm{CaO}_{2}$ levels in these same animals followed a reciprocal pattern to the Met $\mathrm{Hb}$ levels and by the $2 \mathrm{nd} h$ had decreased significantly $\left(\mathrm{F}_{5,55}=31.7\right.$; $p<0.001$, repeated measures one-way ANOVA) (Fig. 2b). This relationship is further illustrated by a correlation of all of the simultaneously measured fetal $\mathrm{CaO}_{2}$ (percent decrease from baseline $\mathrm{CaO}_{2}$ value) and $\mathrm{Met} \mathrm{Hb}$ values from all of the 12 infusions. A significant negative relationship was observed $(p<0.001, r=$ $-0.73, n=115$; Fig. 4).

The fetal $\mathrm{PaO}_{2}$ values of the nitrite infusion studies qualitatively paralleled the $\mathrm{CaO}_{2}$ levels (data not shown). The mean preinfusion $\mathrm{PaO}_{2}$ levels fell from $19.3 \pm 2.6$ to $15.7 \pm 2.4 \mathrm{~mm} \mathrm{Hg}$ by
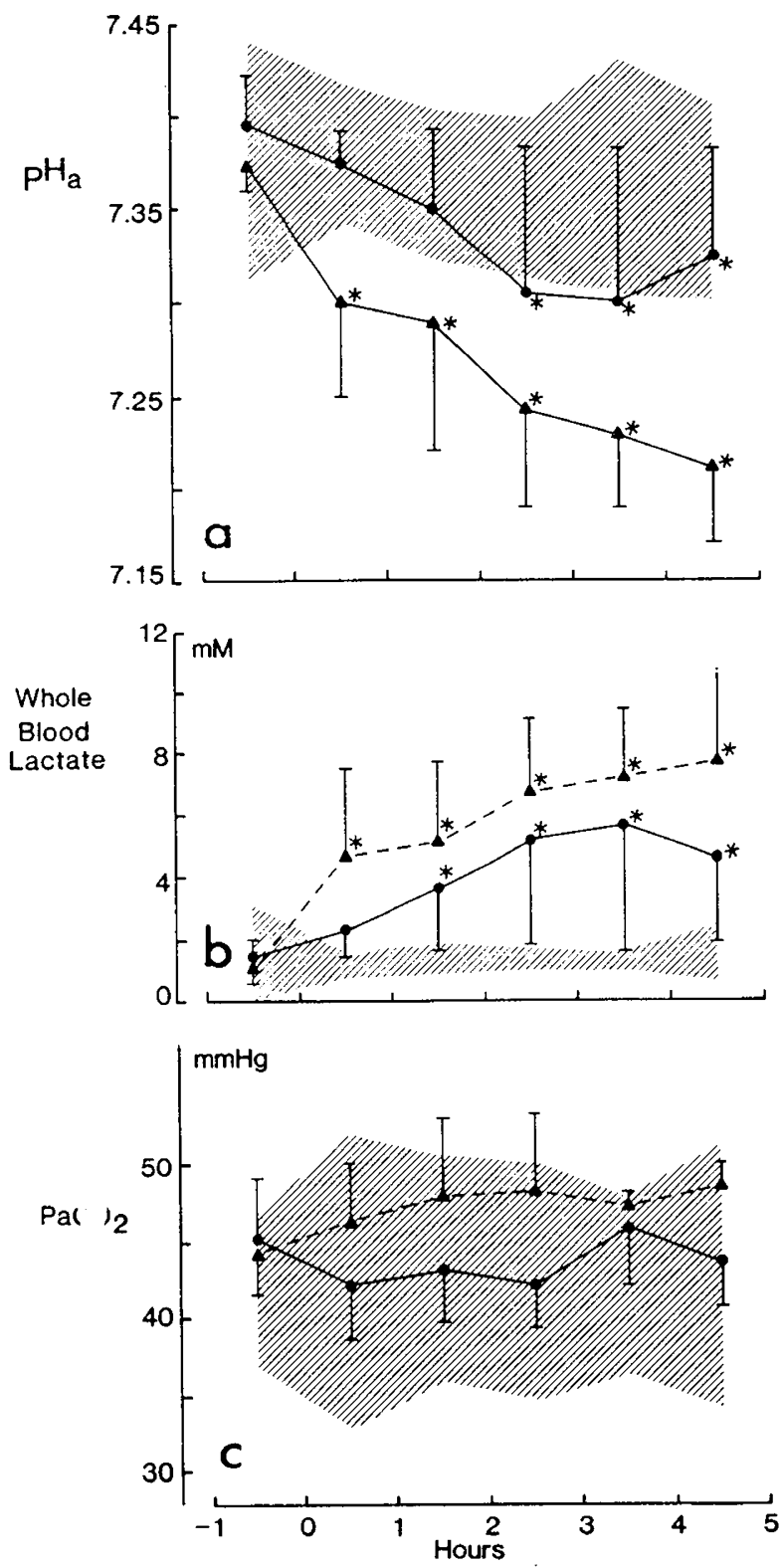

Fig. 3. Mean changes over time in $\mathrm{pH}_{\mathrm{a}}(a)$, whole blood lactate $(b)$, and $\mathrm{PaCO}_{2}(c)$. (See Fig. 2 for legend.) 


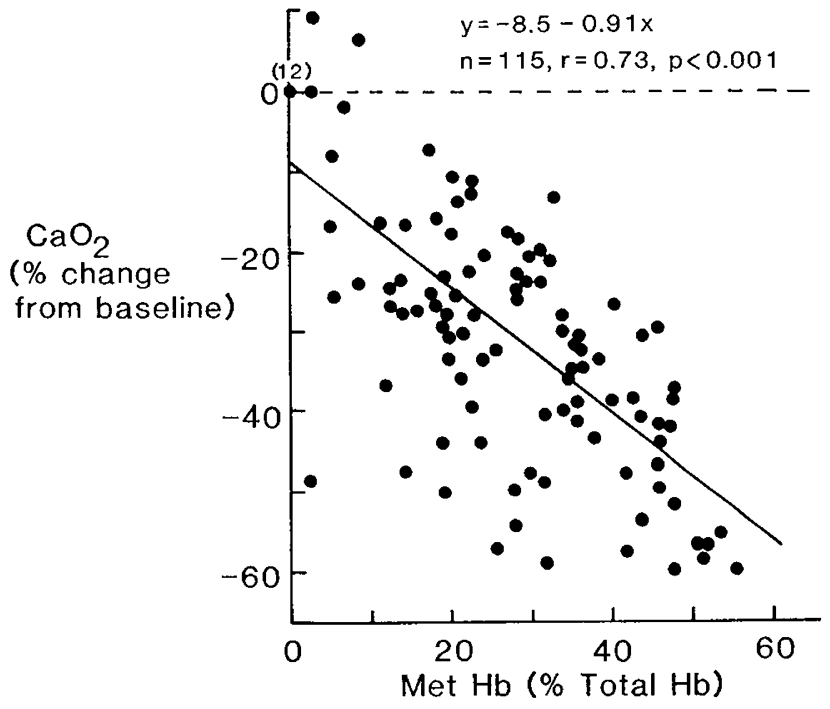

Fig. 4. Relationship of all paired fetal $\mathrm{Met} \mathrm{Hb}$ and $\mathrm{CaO}_{2}$ (percent change from preinfusion baseline) values in all nitrite infusion studies.

the 2 nd $h$ where they remained unchanged until the end of the study.

Despite these marked changes in $\mathrm{Met} \mathrm{Hb}, \mathrm{CaO}_{2}$, and $\mathrm{PaO}_{2}$ during the first $2 \mathrm{~h}$ of the nitrite infusion, the $\log \mathrm{Ep}$ values did not increase until the 4 th $h$ of study $\left(F_{5,55}=36.2 ; p<0.001\right.$, repeated measures one-way ANOVA) (Fig. $2 c$ ). During the 5th and final study $\mathrm{h}$, there was a further significant incremental increase in the log Ep compared to the previous hour $(p<0.01$, Newman Keuls' procedure). When compared to both the control and L-lactic infused groups, the change in log Ep over time was significantly greater in the nitrite infused group $\left(\mathrm{F}_{10,115}=4.11 ; p\right.$ $<0.001$, repeated measures two-way ANOVA).

The interpretation of the results of the nitrite infusion studies is complicated by changes in fetal acid base status. Although $\mathrm{pH}_{\mathrm{a}}$ did not decrease in all animals, mean $\mathrm{pH}_{\mathrm{a}}$ for the group fell significantly by the $3 \mathrm{rd} \mathrm{h}$ of infusion (Fig. $3 a$ ). This fall in $\mathrm{pH}_{\mathrm{a}}$ was due to the development of a metabolic acidosis which would be accounted for largely by the nearly 4 -fold rise in whole blood lactic acid levels (Fig. $3 b$ ).

In the five fetuses infused with exogenous L-lactic acid, comparable changes in $\mathrm{pH}_{\mathrm{a}}$ and whole blood lactic acid were observed, while constant $\mathrm{PaCO}_{2}$ levels were maintained (Fig. $3 a, b$, and $c$ ).

Although by the $3 \mathrm{rd} \mathrm{h}$ of the L-lactic acid infusion mean $\mathrm{CaO}_{2}$ had fallen significantly to a comparable degree as the nitrite group (to approximately $60 \%$ of preinfusion levels), there was no change in $\log \mathrm{Ep}$. This fall in $\mathrm{CaO}_{2}$ was most likely due to a shift in the oxygen dissociation curve (Bohr effect) since $\mathrm{PaO}_{2}$ values of the L-lactic acid infused group were not significantly affected.

During the L-lactic acid infusion, mean arterial blood pressure and fetal heart rate were unchanged $(53 \pm 4.3 \mathrm{~mm} \mathrm{Hg}$ and 158 $\pm 12 \mathrm{bpm}$, respectively). This was identical to what was observed for the control group $(54 \pm 4.8 \mathrm{~mm} \mathrm{Hg}$ and $159 \pm 21 \mathrm{bpm}$, respectively) but was not the case in the nitrite-infused group. In this latter group blood pressure fell transiently during the 1 st $h$ from $51 \pm 6.5$ to $45 \pm 5.0 \mathrm{~mm} \mathrm{Hg}(p<0.01)$, but in subsequent hours returned to normal. Fetal tachycardia developed during the 1 st $h$ of the nitrite infusion (from $179 \pm 12$ to $210 \pm 15$ $\mathrm{bpm}$ ) and persisted at this level throughout the subsequent $4 \mathrm{~h}$.

The volumes of fetal blood removed during the studies in all three groups of studies were comparable. This ranged from 13 to $22 \mathrm{ml}$ and constituted approximately $4-8 \%$ of the conceptus' blood volume at their corresponding gestational ages. A significant fall in PCV was observed for the control and nitrite infused groups ( 35.7 to $33.8 \%$ and 29.9 to $27.4 \%$, respectively, $p<0.01$, paired $t$ test). Inexplicably, the PCV of the L-lactic acid group increased slightly (34.6 to $36.0 \% ; p<0.05)$.

\section{DISCUSSION}

The present sequential studies document an increase in fetal plasma Ep levels after a 3-h period of fetal hypoxemia. Sodium nitrite was intravenously administered to the fetus, resulting in $\mathrm{Met} \mathrm{Hb}$ formation and a concomitant reduction in $\mathrm{CaO}_{2}$. Despite the use of a priming dose of nitrite, the increase in Met $\mathrm{Hb}$ to desirable steady-state levels was not instantaneous such that the fall in $\mathrm{CaO}_{2}$ was progressive over the first $2 \mathrm{~h}$. After this period, however, a sustained decrease in $\mathrm{CaO}_{2}$ levels (to $60 \%$ of preinfusion levels) were maintained. Because of this delay in achieving maximal reductions in $\mathrm{CaO}_{2}$, the 3- to 4-h time period necessary to observe an increase in plasma Ep levels must be considered conservative.

The present data are consistent with previous reports of the fetal Ep response to hypoxemia. Previous investigators have relied on Ep measurements after $3(10)$ or $6 \mathrm{~h}(2,11)$ of hypoxemia. The methods used for the measurement of $\mathrm{Ep}$ in these studies were the less sensitive and less specific in vivo $(10,11)$ and in vitro (12) bioassay techniques. Moreover, the simultaneous $\mathrm{pH}_{\mathrm{a}}, \mathrm{CaO}_{2}$, and $\mathrm{PaO}_{2}$ values were not reported. The present sequential studies which have utilized the more sensitive and specific radioimmunoassay determinations of Ep confirm and further refine the temporal relationships of $E p(7)$ and hypoxemia suggested by earlier investigations.

Moreover, these studies demonstrate that the sheep fetus is capable of responding to hypoxemia in an adult-like manner during the latter fifth of gestation. Zanjani et al. (13) and Schooley and Mahlmann (14) performed cross-sectional studies with adult animals to specifically define the time interval of hypoxemia necessary to achieve increases in plasma Ep levels. Both groups observed that plasma Ep levels in adult rats rose after a 2-h exposure to an immediate and sustained hypobaric stimulus. These and other authors have suggested that the delay in the appearance of Ep is due to the synthesis of new Ep hormone in response to tissue hypoxemia rather than the delayed release of stored hormone (13-15). When taken in the context of their more gradual fall in $\mathrm{CaO}_{2}$, the fetal data in the present studies are remarkably similar to the adult changes. Furthermore, the incremental increase observed in plasma Ep from the 4-5 h in the present study was also noted in the adult rats.

The metabolic acidosis which accompanied fetal hypoxemia in the present study was a confounding variable. In adult animals, respiratory acidosis has been shown to be associated with a suppressive effect on Ep production (16-18). Possible mechanisms explaining this Ep suppression include: 1) a rightward shift in the $\mathrm{Hb}$-oxygen dissociation curve resulting in decreased oxygen affinity; and 2) increased organ blood flow as a result of increased $\mathrm{PaCO}_{2}$. Since $\mathrm{PaCO}_{2}$ remained unchanged in the present study, this latter possibility could not have been operative.

Unlike the adult, the normal fetal $\mathrm{PaO}_{2}$ lies on the steep part of the oxygen dissociation curve. Hence, if $\mathrm{PaO}_{2}$ remains constant, a rightward shift in the fetal $\mathrm{Hb}$-oxygen dissociation curve will result in a decrease in fetal $\mathrm{CaO}_{2}$. If fetal blood flow were to remain constant, this would result in decreased tissue oxygen delivery, potentially impairing tissue oxygenation.

In order to examine this possibility empirically, the L-lactic acid infusions were carried out. No significant change in plasma Ep levels were detected over the 5-h infusion period in the lactic acid-infused fetuses. Hence, it is unlikely that fetal lactic acidemia acts as a stimulator of Ep production. This finding may be viewed as somewhat paradoxical, however, since a substantial fall in $\mathrm{CaO}_{2}$ occurred during the exogenous lactic acid infusion (Fig. $2 b$ ). The nearly $40 \%$ decline from preinfusion $\mathrm{CaO}_{2}$ levels in this group was, in fact, equivalent to that observed with the nitrite infusion studies. The most likely explanation for this 
paradox is that nitrite infusion resulted primarily in fetal hypoxemia followed by a secondary (i.e. endogenous) lactic acidemia. During exogenous L-lactic acid infusion, however, the decline in fetal $\mathrm{CaO}_{2}$ was secondary to combined influences of the Bohr effect on the oxygen dissociation curve as well as to the dependency of fetal $\mathrm{PaO}_{2}$ on maternal intervillous $\mathrm{PaO}_{2}$ (19). The lack of an effect of a detectable increase in Ep under these conditions suggests that the rightward shift in the oxygen dissociation curve continued to permit adequate tissue oxygenation despite a decrease in $\mathrm{CaO}_{2}$. How far this lack of an effect on Ep production might have continued with reductions in $\mathrm{PaO}_{2}$ or under conditions of additional hypoxemic stress is uncertain, however.

The infusion of sodium nitrite to induce fetal hypoxemia has not, to our knowledge, been previously reported. This method was selected because of the ready susceptibility of sheep $\mathrm{Hb}$ to the oxidizing effect of nitrite (20) without detectable maternal effects. Furthermore, since fetal $\mathrm{PaCO}_{2}$ was unaltered, the potential effects of this variable on plasma Ep levels (16) were avoided. However, this method has several disadvantages: the requirement for a continuous infusion to maintain steady state Met $\mathrm{Hb}$ levels, the potential for producing fatal levels of Met $\mathrm{Hb}$, and its pharmacologic effects on the cardiovascular system.

In this regard, interpretation of the results of the present data is confounded somewhat by the cardiovascular effects of nitrite. It is likely that the immediate but transient (30-60 $\mathrm{min}$ ) decrease in fetal arterial blood pressure noted in the 1 st $h$ after the initiation of nitrite infusion was due to its vasodilatory action on the venous system $(21,22)$. Since in adults sodium nitrite has not been shown to have direct myocardial effects, the fetal tachycardia noted after beginning the infusion may have been a secondary reflex to systemic hypotension. However, the subsequent tachycardia was more likely due to the persistent fetal hypoxemia. This finding differs from more acute studies of maternally induced fetal hypoxemia in which fetal bradycardia was a consistent finding $(23,24)$.

In summary, sequentially sampled immunoreactive plasma Ep concentrations were found to be elevated after $3 \mathrm{~h}$ of Met $\mathrm{Hb}$ induced hypoxemia in chronically catheterized fetal sheep. Control animals demonstrated no change in Ep or in any of the other study parameters. The results of Met $\mathrm{Hb}$-induced hypoxemia were confounded by the development of a significant metabolic acidemia during the $3 \mathrm{rd}$ h of study. Since the infusion of exogenous L-lactic acid infusions to achieve comparable levels of acidemia in five additional fetuses was not associated with an increase in fetal plasma $\mathrm{Ep}$ (despite a $40 \%$ fall in oxygen content), a primary effect of $\mathrm{pH}$ on $\mathrm{Ep}$ increase was ruled out. Thus, the temporal response of plasma Ep in the late gestation fetal sheep to sustained hypoxemia appears to be qualitatively similar to the adult, thus demonstrating mature fetal Ep responsiveness. These animal studies provide a relevant framework by which to begin to evaluate the significance of plasma Ep measurements made in the human fetus during labor and delivery.
Acknowledgments. The authors express their appreciation to Mrs. Kathleen Petzold for her technical expertise and to Ms. Donna Perry for her secretarial assistance.

\section{REFERENCES}

1. Fisher JW 1984 Control of erythropoietin production. Proc Soc Exp Biol Med 173:289-305

2. Matoth Y, Zaizov R 1971 Regulation of erythropoiesis in the fetal rat. Isr J Med Sci 7:839-843

3. Peschle C 1980 Erythropoiesis. Ann Rev Med 31:303-314

4. Zanjani ED, Banisadre M, Ascensao JL 1982 Evidence for independent regulation of erythropoiesis in the fetus. Clin Res 30:333(abstr)

5. Zanjani ED, Gordon AS 1971 Erythropoietin production and utilization in fetal goats and sheep. Isr J Med Sci 7:850-856

6. Alfrey Jr CP, Riggs SA 1981 Erythropoietin-an elusive hormone. J Lab Clin Med 97:141-143

7. Garcia JF, Sherwood J, Goldwasser E 1979 Radioimmunoassay of erythropoietin. Blood Cells 5:405-419

8. Evelyn KA, Malloy HT 1938 Microdetermination of oxyhemoglobin, methemoglobin and sulhemoglobin in a single sample of blood. J Biol Chem 126:655-665

9. Sheldon RE, Peeters LLH, Jones MD Jr, Makowski EL, Meschia G 1979 Redistribution of cardiac output and oxygen delivery in the hypoxemic fetal lamb. Am J Obstet Gynecol 135:1071-1978

10. Zanjani ED, Peterson EN, Gordon AS, Wasserman LR 1974 Erythropoietin production in the fetus: Role of the kidney and maternal anemia. J Lab Clin Med 83:281-287

11. Zanjani ED, Mann LI, Burlington H, Gordon AS, Wasserman LR 1974 Evidence for a physiologic role of erythropoietin in fetal erythropoiesis. Blood 44:285-290

12. Meberg A 1980 Plasma erythropoietin levels in fetal and newborn rats: Response to hypoxia. Exp Hematol 8:615-619

13. Zanjani ED, McLaurin WD, Gordon AS, Rapport IA, Gibbs JM, Gidari S 1971 Biogenesis of erythropoietin: role of the substrate for erythrogenin. J Lab Clin Med 77:751-758

14. Schooley JC, Mahlmann L-J 1972 Erythropoietin production in the anephric rat. I. Relationship between nephrectomy time of hypoxic exposure and erythropoietin production. Blood 39:31-38

15. Erslev AJ 1975 Renal biogenesis of erythropoietin. Am J Med 58:25-30

16. Miller ME, Howard D 1979 Modulations of erythropoietin concentrations by manipulation of hypercarbia. Blood Cells 5:389-403

17. Miller ME, Rørth M, Parving HH, Howard D, Reddington I, Valeri CR, Stohlman F Jr $1973 \mathrm{pH}$ effect on erythropoietin response to hypoxia. N Engl J Med 288:706-710

18. Schooley JC, Mahlmann L-J 1975 Hypoxia and the initiation of erythropoietin production. Blood Cells 1:429-448

19. Faber JJ, Thornburg KL 1983 Placental Physiology: Structure and Function of Fetomaternal Exchange. Raven Press, New York, pp 63-74

20. Calabrese EJ, Moore GS, Ho S-C 1980 Low glucose-6-phosphate dehydrogenase (G-6-PD) activity in red blood cells and susceptibility to copper-induced oxidative damage. Environ Res 21:366-372

21. Carr CJ (1975) Pharmacological properties. In: Needleman P (ed) Organic Nitrates. Springer-Verlag, New York, pp 39-56

22. Mason DT, Zelis A, Amsterdam EA 1971 Actions of the nitrites on the peripheral circulation and myocardial oxygen consumption: significance in the relief of angina pectoris. Chest 59:296-305

23. Cohn HE, Sacks EJ, Heymann MA, Rudolph AM 1974 Cardiovascular responses to hypoxemia and acidemia in fetal lambs. Am J Obstet Gynecol 120:817-824

24. Peeters LLH, Sheldon RE, Jones MD Jr, Makowski EL, Meschia G 1979 Blood flow to fetal organs as a function of arterial oxygen content. Am J Obstet Gynecol 135:637-646 